\section{Flow stripes, GPR stratigraphy and RADARSAT imagery}

In a recent paper, Campbell and others (2008) discussed the lack of correlation between the deep (>100 m) cross-flow folds in radar-detected stratigraphy and surface 'flow stripes'. Their study focused on an area upstream of the now stagnant part of Kamb Ice Stream (KIS), West Antarctica, and they noted the lack of near-surface stratigraphy obtained by higher-frequency radar to help explain the apparent anomaly. Such data do exist and, as we illustrate below, show a good correlation between the flow-stripe image features and the near-surface stratigraphy.

Figure 1 illustrates part of the RADARSAT Antarctic Mapping Mission (AMM) $125 \mathrm{~m}$ mosaic and the position of two of the lines $\left(\mathrm{AA}^{\prime}\right.$ and $\mathrm{BB}^{\prime}$ in figure 2 of Campbell and others, 2008). These lines were also studied in the fieldwork of Smith and others (2002) and Ng and Conway (2004). The groundpenetrating radar (GPR) data used by Smith and others (2002) in the study of buried crevasses in the shear zone of KIS did map near-surface stratigraphy. Lines $\mathrm{LL}^{\prime}$ and $\mathrm{KK}^{\prime}$ in their figure 3 were acquired in fieldwork carried out in the 1997/ 98 austral summer, and correspond to the deep radar lines $\mathrm{AA}^{\prime}$ and $\mathrm{BB}^{\prime}$ of Campbell and others (2008) and lines $X \mathrm{X}^{\prime}$ and $Y Y^{\prime}$ of $\mathrm{Ng}$ and Conway (2004). The choice of $\mathrm{LL}^{\prime}$ and $\mathrm{KK}^{\prime}$ by Smith and others (2002) reflected two of the lines used in the pioneering work of Shabtaie and Bentley (1987).

Details of the processing of the $80 \mathrm{MHz}$ Geophysical Survey Systems Inc. (GSSI) monopulse GPR are given by Smith and others (2002), together with the technique used to date particular layers in the stratigraphy. The depth of the firn layer deposited around $1951(\sim 46 \pm 4$ years prior to the fieldwork) is plotted in Figure 2 for the two test lines and compared with the average $5.3 \mathrm{GHz}$ radiometric variation. Radiometric smoothing of the RADARSAT data was performed primarily along the direction of the flow-stripe feature. First, the orientations of the flow stripes were estimated with respect to the two lines. Then averaging was

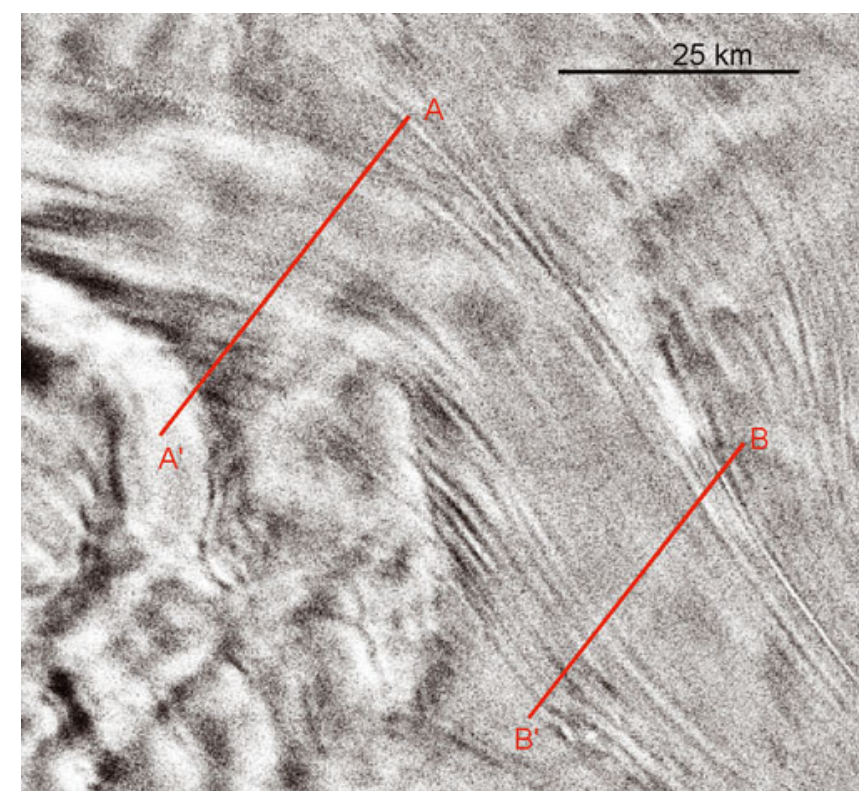

Fig. 1. Positions of the $A A^{\prime}$ and $B B^{\prime}$ lines in KIS superimposed on part of the 1997 RADARSAT AMM $125 \mathrm{~m}$ mosaic data. The 'flow stripes' are typically $\sim 1 \mathrm{~km}$ wide and usually reflect the ice-flow direction. applied with a smoothing function $(\sim 250 \times 800 \mathrm{~m})$ such that the extra averaging was applied in the along-flow-stripe direction. The correlation between the depth of the particular layer and the average radiometry in Figure 2 is remarkable. Some examples of these correlations have been presented at West Antarctic Ice Sheet meetings (Conway and others, http://neptune.gsfc.nasa.gov/wais/pastmeetings/PPT04/ Question3/Conway.ppt; Gray and others, http://neptune. gsfc.nasa.gov/wais/pastmeetings/PPT05/Gray.ppt; King and others, http://neptune.gsfc.nasa.gov/wais/pastmeetings/ abstracts04/King.htm), including results collected during the 2000/01 British Antarctic Survey-University of Texas radar experiment over parts of Bindschadler Ice Stream and a tributary of KIS. This result appears to be general for cold polar firn in West Antarctica and does not depend on the orientation of the test line with respect to the ice motion, or the magnitude of the ice velocity. However, if the strain rates are high enough for crevasse formation then this relationship breaks down.

Figure 3 illustrates the near-surface stratigraphy studied by Smith and others (2002) (top curve) and the deep stratigraphy studied by $\mathrm{Ng}$ and Conway (2004). The weak correlation between the near-surface and deep stratigraphy confirms the conclusion of Campbell and others (2008) that there is a weak correlation between flow stripes and deep folds. This is puzzling because, as isochrones, the nearsurface stratigraphy should evolve smoothly into the deep stratigraphy.

In Figure 3 the upper $300 \mathrm{~m}$ of the deep radar results of line $A^{\prime} A$ are obscured by the illustration of the depth of the 1951 isochronal layer. Note that there is correlation between the bed and the stratigraphy (both deep and nearsurface) at the left edge of the figure where the ice moves over what appears to be a subglacial escarpment. Also, there is correspondence between the near-surface and deep folds in the region vertically above the 'Bed' label, but otherwise the correlation is poor.

These results prompt two questions: why does the shape of cross-flow isochrones and in particular the positions of folds in the stratigraphy change with near-surface depth in a region such as the KIS? and what is the origin of the strong correlation between the RADARSAT image radiometry and near-surface stratigraphy?

The first question has been discussed in depth by Campbell and others (2008), and we make only the following comments: Near-surface stratigraphy (to $\sim 10 \mathrm{~m}$ ) is controlled largely by accumulation which varies locally, depending primarily on surface slope and prevailing winds. But the surface slope is itself influenced by forces acting on the ice and firn, including those that reflect movement over the varied basal topography and other conditions. Also, with time (and depth), isochrone separation becomes more a function of the cumulative history of the strain than of the original accumulation. For example, if the firn in a region of creep or tributary flow undergoes a relatively modest horizontal strain of $10^{-3} \mathrm{a}^{-1}$ in the flow direction, and zero across-flow, then the associated vertical GPR stratigraphy will decrease by $\sim 10 \%$ in only 100 years. Remembering that it takes many hundreds of years to accumulate $100 \mathrm{~m}$ of firn in this region of West Antarctica, and that deeper layers originated further and further upstream, the deeper folds reflect the accumulated strain history much more than the original spatial accumulation pattern. We believe this to be particularly true in this region where the forces, and the 

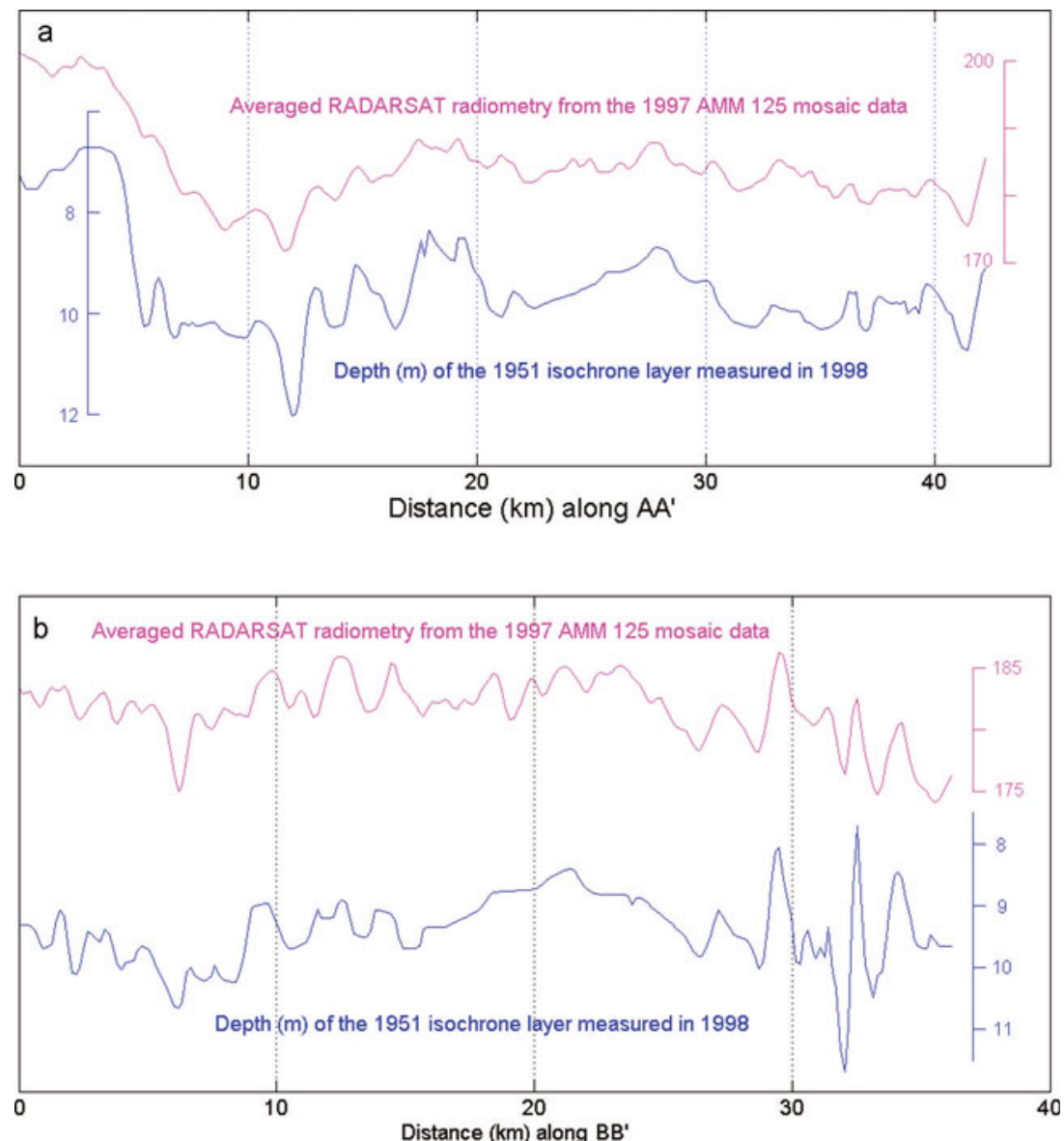

Fig. 2. Depth to a particular isochrone ( $1951, \pm 4$ years) versus the averaged $5.3 \mathrm{GHz}$ radiometry derived from the AMM $125 \mathrm{~m}$ mosaic for lilnes $A^{\prime} A(a)$ and $B^{\prime} B(b)$.

resulting strain history, may be complex (large changes in ice thickness, basal drag, and ice-flow speed and direction). While any discussion of the origin of the flow stripes is beyond the scope of this correspondence, we do note that they appear to originate in KIS downstream from a relatively large change in bed topography. Also, the increasing amplitude of the folds with depth and the downstream compression of the observed patterns ( $\mathrm{Ng}$ and Conway, 2004) imply

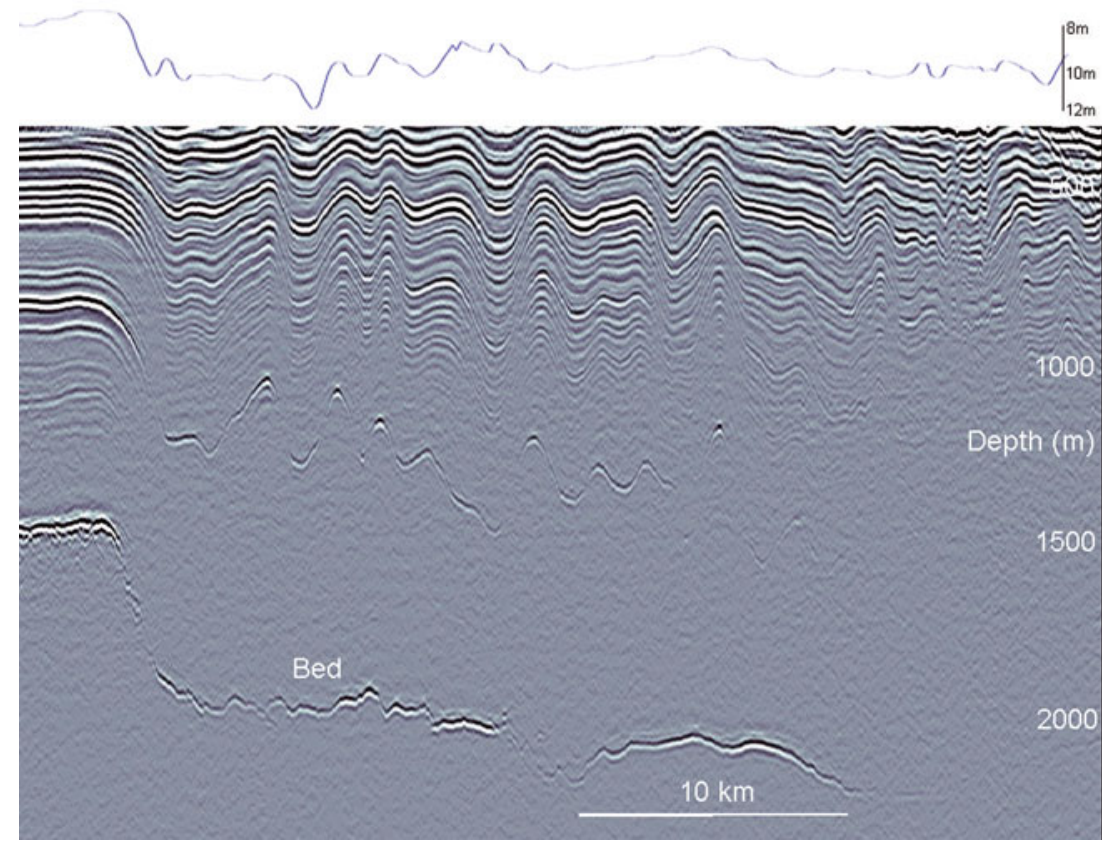

Fig. 3. Comparison of the near-surface stratigraphy ( 1951 isochronal layer, upper blue curve) obtained by Smith and others (2002) and the deep radar results of $\mathrm{Ng}$ and Conway (2004) for the $\mathrm{A}^{\prime} \mathrm{A}$ line in Figure 1. 
that lateral compression is a key component in the generation of the folds. Considering the more brittle nature of the cold upper firn layers, it is perhaps not surprising that the shape of the near-surface folds, and the resulting flow-stripe pattern, may not be preserved in the deep folds.

Secondly, why is there such a strong correlation between the RADARSAT image radiometry and near-surface stratigraphy? The first important point is that the $5.3 \mathrm{GHz}$ radiometric variations in interior West Antarctica reflect a strong volume component to the backscatter; radiometric contrast across flow stripes is greater than that which could arise from backscatter variation with surface slope alone. Also, biases between airborne interferometric synthetic aperture radar (InSAR) and laser-derived topography over ice sheets (Dall and others, 2001; Rignot and others, 2001) demonstrate the importance of subsurface volume backscatter in $5.3 \mathrm{GHz}$ SAR data in cold polar firn, and of the effective depth $(\sim 10 \mathrm{~m})$ from which the integrated backscatter originates.

But what physical structures in the upper $\sim 10 \mathrm{~m}$ of the cold polar firn contribute to the modulation in the backscatter signal? The strong correlation between the 50$100 \mathrm{MHz}$ near-surface GPR results and the off-nadir $5.3 \mathrm{GHz}$ imagery suggests that the source of the variability may be the same for both radar observations. Arcone and others (2004), using a $400 \mathrm{MHz}$ GPR, provide evidence that thin 'wind-crust' ice layers (1-2 mm thick, often associated with widespread hoar-frost events) act as reflectors and that the integrated response from these dielectric discontinuities could lead to the stratigraphic modulations in the nearsurface GPR results. Note that the link to widespread meteorological conditions satisfies the requirement that the resulting modulation would be isochronal over relatively large distances. During the formation of the thin ice layers they reflect the current shape of the surface and, as such, have a roughness and dielectric constant discontinuity such that the integrated response from many such layers could also contribute significantly to off-nadir $5.3 \mathrm{GHz}$ backscatter. The increased $5.3 \mathrm{GHz}$ radiometric brightness associated with the peaks (shorter delay time) in the GPR stratigraphy could simply reflect the fact that there would be more ice layers per meter of depth in the lower-accumulation regions than in the higher-accumulation areas. If this explanation proves credible then it may also be instrumental in explaining the empirical correlation between accumulation and spaceborne scatterometer (e.g. Drinkwater and others, 2001) and radiometer signatures (e.g. Arthern and others, 2006).

\section{ACKNOWLEDGEMENTS}

The RADARSAT AMM was a joint Canadian Space Agency NASA project led by K. Jezek, of The Ohio State University, USA. We thank N. Lord and T. Gades for help in the 1997/98 fieldwork. The formation of 'wind-crust ice layers' in polar firn and the link to hoar-frost layers was discussed with the late R. Koerner and M. Demuth of the Geological Survey of Canada. Their help is gratefully acknowledged.

Canada Centre for Remote Sensing,

Laurence GRAY

588 Booth Street,

Ottawa,

Ontario K1A OY7,

Canada

E-mail: Laurence.Gray@nrcan.gc.ca

Department of Earth and

Howard CONWAY

Space Sciences,

University of Washington,

Seattle, Washington 98195-1310, USA

British Antarctic Survey,

Ed KING

Natural Environment Research Council,

Madingley Road,

Cambridge CB3 OET,

UK

Polar Science Center,

Ben SMITH

Advanced Physics Laboratory,

University of Washington,

1013 NE 40th Street,

Seattle, Washington 98105-6698, USA

\section{September 2008}

\section{REFERENCES}

Arcone, S.A., V.B. Spikes, G.S. Hamilton and P.A. Mayewski. 2004. Stratigraphic continuity in $400 \mathrm{MHz}$ short-pulse radar profiles of firn in West Antarctica. Ann. Glaciol., 39, 195-200.

Arthern, R.J., D.P. Winebrenner and D.G. Vaughan. 2006. Antarctic snow accumulation mapped using polarization of $4.3 \mathrm{~cm}$ wavelength microwave emission. J. Geophys. Res., 111(D6), D06107. (10.1029/2004JD005667.)

Campbell, I., R. Jacobel, B. Welch and R. Pettersson. 2008. The evolution of surface flow stripes and stratigraphic folds within Kamb Ice Stream: why don't they match? J. Glaciol., 54(186), 421-427.

Dall, J., S. Madsen, K. Keller and R. Forsberg. 2001. Topography and penetration of the Greenland ice sheet measured with airborne SAR interferometry. Geophys. Res. Lett., 28(9), 1703-1706.

Drinkwater, M.R., D.G. Long and A.W. Bingham. 2001. Greenland snow accumulation estimates from satellite radar scatterometer data. J. Geophys. Res., 106(D24), 33,935-33,950.

$\mathrm{Ng}, \mathrm{F}$. and H. Conway. 2004. Fast-flow signature in the stagnated Kamb Ice Stream, West Antarctica. Geology, 32(6), 481-484.

Rignot, E., K. Echelmeyer and W. Krabill. 2001. Penetration depth of interferometric synthetic-aperture radar signals in snow and ice. Geophys. Res. Lett., 28(18), 3501-3504.

Shabtaie, S. and C.R. Bentley. 1987. West Antarctic ice streams draining into the Ross Ice Shelf: configuration and mass balance. J. Geophys. Res., 92(B2), 1311-1336.

Smith, B.E., N.E. Lord and C.R. Bentley. 2002. Crevasse ages on the northern margin of Ice Stream C, West Antarctica. Ann. Glaciol., 34, 209-216. 